\title{
Mycobacterium avium subspecies paratuberculosis infection and autoimmune condition: investigation of family members
}

\author{
Margherita Sisto', Massimo D'Amore², C.Thomas Dow ${ }^{3}$, Sabrina Lisi' \\ I Department of Human Anatomy and Histology, University of Bari, Bari, Italy \\ 2 Department of Internal Medicine and Public Medicine, Section of Rheumatology, University of Bari, Italy \\ 3 Department of Ophthalmology, University of Wisconsin, United States
}

Key words: Mycobacterium avium paratuberculosis, autoimmune, milk

Infezione da Mycobacterium avium subspecies paratuberculosis e autoimmunità: studio su componenti di una stessa famiglia

\section{SUMMARY}

Mycobacterium avium subspecies paratuberculosis (MAP) causes Johne's disease, a chronic granulomatous intestinal condition which affects ruminants, including cattle, sheep, goats, and farmed deer. In more recent studies water and milk supplies have both been suggested as vehicles of MAP transmission between cattle and humans. Recently our group observed immune responses to MAP in an Italian patient with Hashimoto's thyroiditis and Melkersson-Rosenthal syndrome. The focus of our work was evaluate the hypothesis of a possible MAP infection in other members of the same family.

\section{INTRODUCTION}

Recently our group observed immune responses to Mycobacterium avium subspecies paratuberculosis (MAP) in an Italian patient with Hashimoto's thyroiditis and Melkersson-Rosenthal syndrome (2). MAP causes Johne's disease, a chronic granulomatous intestinal condition which affects ruminants, including cattle, sheep, goats, and farmed deer (7). In more recent studies water and milk supplies have both been suggested as vehicles of MAP transmission between cattle and humans. Several, risk of human exposure to MAP exist, and the primary focus has mainly been on dairy products. Milk may be contaminated directly within the udder or indirectly as a result of fecal contamination (10). This bacterium has attracted considerable interest owing to the rapidly growing body of scientific evidence suggesting that human infection with this micro-organism may be one of the causative agents in Crohn's disease (7). There is still much to be learned about MAP and the diseases that it may cause in humans. Recent findings by Sechi and Dow link diabetes to Crohn's disease, since they found MAP bacteremia in autoimmune diabetes $(3,12,13)$. Consumption of cow's milk early in life is a recognized risk factor in the development of these diseases, and environmental micro-organisms are thought to trigger autoimmune responses in genetically susceptible individuals (3).

In the Italian patient with Hashimoto's thyroiditis and Melkersson-Rosenthal syndrome, the examination of the anamnesis, of the patient's family history and lifestyle lead us to hypothesize that there was the possibility of a MAP infection in other members of the same family. The family lives, from the childhood, in a farm with cattle, in an Italian region in which the MAP infection in animal farm is widespread. For a long period of the life, family members drank cow's milk produced directly from their farm and actually continue the diet based on dairy products. On general examination, two of the brothers of the case reported above, referred to suffer for many years of bowel disorders and following laboratory investigation positive levels of thyroid anti-thyroglobulin antibodies $(1323 \mathrm{mU} / \mathrm{ml}$; normal range $<40 \mathrm{UI} / \mathrm{mL})$ and anti-thyroperoxidase antibodies $(>1000 \mathrm{mU} / \mathrm{ml}$; normal range $<35 \mathrm{mU} / \mathrm{ml}$ ) were detected.

Based on the observations deducted from family clinical picture and laboratory tests, we hypothyzed the existence of MAP infection in the two brothers.

We performed Reverse-Transcriptase Polymerase Chain Reaction (RT-PCR) to reveal the presence of viable MAP using mRNA extracted from peripheral blood mononuclear cells of these subjects, amplifying IS900 sequences which are unique to MAP. The positive MAP control was ATCC 19698 DNA, and a band co-migrating with the ATCC 19698 DNA at the predicted amplicon size was considered positive. Bands were purified and sequenced (San Raffaele Biomedical Science Park, Milan, Italy). The sequence identity of the final amplicon was compared with the Genebank accession group EF514830 sequence for MAP IS900 using the International Nucleotide Sequence Database (8) and sequence alignment analyses. The PCR data (Figure) show bands that co-migrates with the positive control at the predicted 298 bp amplicon size. The sequenced DNA of the representative sample bands showed $100 \%$ identity with MAP IS900.

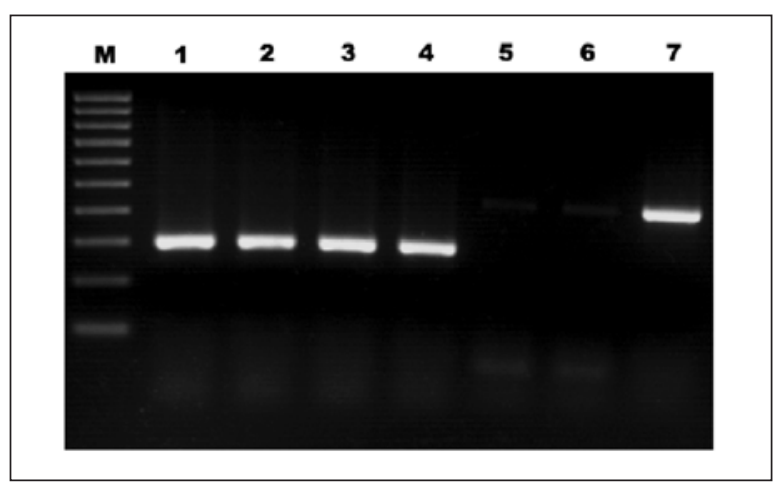

Figure. Agarose gel electrophoresis of amplified IS900 fragments. M, molecular marker. Lane I, Mycobacterium avium subspecies paratuberculosis positive control. Lane 2, 3, 4, three family members. Lane 5, distilled water negative control. Lane 6, Mycobacterium avium subspecies paratuberculosis negative control subject. RT-PCR of internal control GADPH (lane 7).

\section{DISCUSSION}

There is current evidence that a percentage of healthy individuals have MAP DNA in their blood, the significance of which remains to be determined (6).

However, there are specific states of immune dysfunction or genetic predisposition that could promote mycobacterial infections.

Identification of MAP in the blood of these three family members could be more than a coincidence.

It is common knowledge that human pathogens often express proteins with a high antigenic potential and strong homolo-

\section{Corresponding author: Margherita Sisto}

Department of Human Anatomy and Istology, University of Bari Medical School,

Piazza G. Cesare I, Bari, Italy - Tel.: +39 08054783 I5 - Fax: +39 0805478327

E-mail:m.sisto@anatomia.uniba.it 
gies with human proteins.

Evolutionary pressures based upon the necessity to escape host specific immune responses may have determined this phenomenon, known as "molecular mimicry".

It is reasonable to assume that certain individuals can develop abnormal immune responses upon contact with an antigen that mimics a self-protein.

The human heat shock protein (Hsp) 60, for example, with a high degree of homology with Hsp65 of MAP, shares a sequence homology with a wide range of autoantigens including those of Hashimoto's thyroiditis (5).

Epitope mimicry is widely thought to be the mechanism for the induction of autoimmune disease.

The theory is that an infectious agent (parasite, bacteria, yeast or virus) displays epitopes immunologically resembling host determinants and due to the minor antigenic differences between the two, the pathogen's epitope is able to induce an immune response that breaks tolerance to the host epitope. The cross-reactive $\mathrm{T}$ or $\mathrm{B}$ cell is then able to induce a pathogenic autoimmune response that leads to disease (9).

\section{CONCLUSION}

Founding MAP infection in family members with high titles of anti-thyroid antibodies could be according to the hypothesis that molecular mimicry is one of the mechanism by which autoimmune diseases can occur in association with infectious agents.

Up to date, the currently available evidence is insufficient to confirm or disprove that Mycobacterium paratuberculosis is a causative agent of human autoimmune diseases.

Prospective studies are needed to test this hypothesis over a wider range of possible etiologies that include combination of infectious, immunological and genetic factors.

\section{REFERENCES}

1. Apaydin R, Bilen N, Bayramgürler D, et al. Detection of Mycobacterium tuberculosis DNA in a patient with Melkersson-Rosenthal syndrome using polymerase chain reaction. Br J Dermatol 2000; 142: 1251-2.

2. D'Amore M, Lisi S, Sisto M, et al. Molecular identification of Mycobacterium avium subspecies paratuberculosis in an Italian patient with Hashimoto's thyroiditis and Melkersson-Rosenthal syndrome. J Med Microbiol 2009, Oct 1. [Epub ahead of print].

3. Dow CT. Cows, Crohn's and more: Is Mycobacterium paratuberculosis a superantigen? Medical Hypotheses 2008; 71: 858-61.

4. Gottwald W. Melkersson-Rosenthal syndrome. 2: diagnosis, differential diagnosis, course, prognosis, neuropathology, therapy. Fortschr Med 1981; 99: $326-30$

5. Jones DB, Coulson AF, Duff GW. Sequence homologies between hsp60 and autoantigens. Immunol Today 1993; 14: 115-8.

6. Juste RA, Elguezabal N, Garrido JM, et al. On the prevalence of Mycobacterium avium subspecies paratuberculosis DNA in the blood of healthy individuals and patients with inflammatory bowel disease. PLoS One 2008; 3: e2537.

7. Naser SA, Ghobrial G, Romero C, et al. Culture of Mycobacterium avium subspecies paratuberculosis from the blood of patients with Crohn's disease. Lancet 2004; 364:1039-44.

8. National Institutes of Health. International nucleotide sequence database collaboration. Available from URL: http://www.ncbi.nlm.nih.gov

9. Oldstone MB. Molecular mimicry, microbial infection, and autoimmune disease: evolution of the concept. Curr Top Microbiol Immunol 2005; 296: 1-17.

10. Pickup RW, Rhodes G, Bull TJ, et al. Mycobacterium avium subspecies paratuberculosis in lake catchments, in river water abstracted for domestic use, and in effluent from domestic sewage treatment works: diverse opportunities for environmental cycling and human exposure. Appl Environ Microbiol 2006; 72: 4067-77.

11. Scagliusi P, Sisto M, Lisi S, et al. Hashimoto's thyroiditis in Melkersson-Rosenthal syndrome patient: casual association or related diseases? Panminerva Med 2008; 50: 255-7.

12. Sechi LA, Scanu AM, Molicotti P, et al. Detection and Isolation of Mycobacterium avium subspecies paratuberculosis from intestinal mucosal biopsies of patients with and without Crohn's disease in Sardinia. Am J Gastroenterol 2005; 100: 1529-36.

13. Sechi LA, Paccagnini D, Salza S, et al. Mycobacterium avium subspecies paratuberculosis bacteremia in type 1 diabetes mellitus: an infectious trigger? Clin Infect Dis 2008; 46: 148-9. 